\title{
PELAKSANAAN EKSEKUSI SERTIPIKAT HAK TANGGUNGAN DALAM UPAYA PENYELESAIAN KREDIT MACET DI PENGADILAN NEGERI
}

\author{
Yagus Suyadi ${ }^{1}$, Puji Prastiyo ${ }^{2}$ \\ 1. Badan Pertanahan Nasional Republik Indonesia \\ 2. Pengadilan Negeri Nganjuk \\ Email: pujiprastiyo432@gmail.com
}

\begin{abstract}
ABSTRAK
Dalam lingkungan perbankan suatu kredit digolongkan sebagai kredit macet adalah semenjak tidak ditepatinya atau dipenuhinya ketentuan yang tercantum dalam perjanjian kredit, yaitu apabila debitur selama tiga kali berturut-turut tidak membayar angsuran dan bunganya. Salah satu cara untuk mengatasi adanya kredit macet tersebut, maka jalan yang paling efektif ditempuh oleh pihak bank dalam rangka mengembalikan uang yang di pinjamnya adalah dengan cara melalui eksekusi terhadap sertipikat hak tanggungan sebagai mana di atur dalam undang-undang No 4 tahun 1996. Bentuk eksekusi adalah parate executie, bahwa pelaksanaan parate executie merupakan cara termudah dan sederhana bagi kreditor untuk memperoleh kembali piutangnnya, manakala debitor cidera janji dibandingkan dengan eksekusi yang melalui bantuan atau campur tangan Pengadian Negeri. Tujuan penulisan tesis ini adalah: (1) Untuk menganalisa Pengadilan Negeri dalam menjalankan eksekusi hak tanggungan. (2) Untuk menganalisa akibat hukum yang timbul sebagai konsekuensi dari tugas Pengadilan Negeri dalam menjalankan eksekusi jaminan Hak Tanggungan untuk menyelesaikan kredit macet.

Jenis penelitian yang digunakan dalam tesis ini adalah yuridis normatif. Dalam penelitian ini juga digunakan pendekatan perundang-undangan (Statute Approach) dan pendekatan konsep (conceptual approach) yaitu penulis ingin menganalisa tentang pelaksanaan eksekusi sertifikat hak tanggungan dalam upaya penyelesaian kredit macet di pengadilan Negeri kemudian seluruh data yang ada dianalisa secara deskriptif kualitatif sehingga mendapat jawaban kesimpulan akhir dari rumusan masalah penelitian yang diteliti.

Hasil penelitian dalam tesis ini adalah: (1) Pengadilan Negeri dalam menjalankan eksekusi sertifikat hak tanggungan tidak saja meliputi sebagaimana ketentuan yang diamanatkan dalam Pasal 6 Undang-Undang Hak Tanggungan, Pasal $224 \mathrm{HIR} / 258 \mathrm{RBg}$, juga mamberikan pertimbangan hukum terhadap kreditor dan debitor. Kemudian dalam menyikapi permasalahan mengenai eksekusi Hak Tanggungan tersebut dengan berlandaskan pada ketentuan Pasal 218 (2) RBg maka dalam hal debitor/ termohon lelang tidak bersedia keluar dari obyek Hak Tanggungan atau jaminan atau barang yang dilelang maka cukup mengajukan permohonan kepada Ketua Pengadilan Negeri untuk dilakukan eksekusi pengosongan dan hal ini dalam beberapa kesempatan telah dilaksanakan dan berjalan dengan baik, sekalipun dalam proses atau pelaksanaan eksekusi Hak Tanggungan tersebut salah satunya dilakukan dengan bantuan kekuatan hukum. (3) Akibat hukum yang timbul sebagai konsekuensi dari tugas Pengadilan Negeri dalam menjalankan eksekusi jaminan Hak Tanggungan untuk menyelesaikan kredit macet adalah debitor harus patuh untuk melunasi hutangnya, bila tidak patuh maka dipaksa melalui lelang, cekal dan atau paksa badan dan kalau keberatan terhadap eksekusi dapat mengajukan gugatan, sedangkan terhadap kreditor/bank yang tidak puas atas pengurusan hah tanggungan dapat mengurus sendiri piutangnya, serta terhadap Pihak Ketiga yang keberatan dapat mengajukan perlawanan (derdenverzet).

Kata Kunci : Eksekusi Sertipikat Hak Tanggungan, Kredit, Pengadilan Negeri.
\end{abstract}

\section{ABSTRACT}

In the banking environment of a loan is classified as non-performing loans since no ditepatinya or fulfill the provisions of the credit agreement, that if the debtor for three times in a row did not pay the installments and interest. One way to overcome a bad credit, then the most effective path taken by the bank in order to return the money that was borrowed its way through the execution of the mortgage certificates which are regulated by law No. 4 of 1996. This form of execution is parate executie, that executie parate execution is the easiest and simplest way for creditors to recover piutangnnya, when borrowers default than the execution through the help or interference District Court. 
Purpose of this thesis was largely: (1) To analyze the District Court in the running executable mortgage. (2) To analyze the legal consequences that arise as a consequence of the Court in carrying out the task execution Mortgage guarantees to resolve bad loans.

This type of research used in this thesis is normative. In this study also used the approach of legislation (Statute Approach) and the approach of the concept (conceptual approach) that the author wanted to analyze the execution of the certificate of mortgage in the settlement of bad loans in the State court and then all data were analyzed by descriptive qualitative so it gets an answer conclusions of an investigational formulation of research problems.

The results in this thesis are: (1) the District Court in carrying out executions encumbrance certificate not only include the provisions as stipulated in Article 6 of the Mortgages Act, Article $224 \mathrm{HIR} / 258 \mathrm{RBg}$, mamberikan also legal considerations for creditors and debtors. Then in addressing the problem concerning the execution of the Mortgage based on the provisions of Article 218 (2) RBg then in terms of the debtor / defendant is not willing to come out of the auction object Mortgages or guarantee or auction item then simply submit an application to the Chairman of the District Court to do execution emptying and on several occasions it has been implemented and running well, though in the process or the execution of Mortgage is one of them carried out with the help of the force of law. (3) The legal consequences that arise as a consequence of the Court in carrying out the taske execution Mortgage guarantees to resolve non-performing loans are debtors to repay their debts should be obedient, if not obedient then forced through the auction block and or forced body and if you object to the execution can be filed suit, while the creditors / banks are not satisfied with the maintenance of dependents to take care of yourself hub receivable, as well as against third parties who may submit objections resistance (derdenverzet).

Keywords: Execution of Certificate of Deposit Rights, Credit, District Court.

\section{A. PENDAHULUAN}

Pembangunan ekonomi, sebagai bagian dari pembangunan nasional, merupakan salah satu upaya untuk mewujudkan kesejahteraan rakyat yang adil dan makmur berdasarkan Pancasila dan Undang-Undang Dasar 1945. Berdasarkan data dari Badan Pusat Statistik (BPS) telah mengeluarkan laporan Kuartal II 2017,yang menyatakan bahwa pertumbuhan ekonomi Indonesia mencapai 5,01 persen. Sedangkan data dari IMF menunjukan, posisi Indonesia jauh berada di atas pertumbuhan ekonomi dunia sebesar 3,5 persen.

Indonesia berada di posisi tiga besar di kelompok negara G-20 bersama India (7,2 persen), dan China (6,6 persen). Jauh di atas negara besar lain seperti Australia (3,1 persen), Korea Selatan (2,7 persen), Amerika Serikat (2,3 persen), dan Jepang (1,2 persen). Hal ini menunjukan ditengah situasi perekonomian global yang masih tak menentu, pondasi ekonomi Indonesia secara keseluruhan tetap kokoh. Mendasarkan pada data tersebut Lembaga Pemeringkat Kredit Standard And Poor (S\&P) menaikan peringkat kredit Indonesia menjadi Investment Grade. Moody's Investors Service dan Fitch Ratings juga memberikan penilaian positif terhadap penilaian kredit Indonesia.
Sejalan dengan kegiatan pembangunan nasional di bidang ekonomi membutuhkan penyediaan modal yang cukup besar, karena merupakan salah satu faktor penentu dalam pelaksanaan pembangunan nasional, sebagai sarana mendorong pertumbuhan ekonomi nasional sekaligus sebagai factor penentu statbilitas nasional Negara Indonesia.

Selanjutnya untuk menarik investasi di sektor swasta, pemerintah juga akan meningkatkan di sektor investasi dengan menawarkan berbagai kemudahan yang ada. Sebagai upaya untuk mendorong pertumbuhan investasi, Pemerintah segera meluncurkan paket kebijakan ke-16 pada pertengahan tahun 2017, paket tersebut diharapkan bisa menyangkut semua Kementerian dan Lembaga hingga Pemerintah Daerah.

Kredit memiliki tujuan, fungsi dan manfaat. Pertama, tujuan dari kredit antara lain : 1) mendapatkan keuntungan, bentuk bunga yang diterima oleh bank sebagai balas jasa dan biaya administrasi kredit yang dibebankan kepada nasabah; 2). membantu usaha nasabah, dana investasi maupun dana untuk modal kerja, maka pihak debitur dapat mengembangkan dan memperluas usahanya; 3). membantu pemerintah, semakin banyak kredit yang disalurkan berarti adanya peningkatan pembangunan diberbagai sektor. 
Selanjutnya fungsi-fungsi kredit dalam garis besarnya, antara lain : 1). Kredit dapat meningkatkan daya guna (utility) dari uang; 2). Kredit dapat meningkatkan daya guna (utility) dari barang; 3). Kredit meningkatkan peredaran dan lalu lintas uang; 4). Kredit adalah salah satu alat stabilisasi ekonomi; 5). Kredit menimbulkan kegairahan berusaha masyarakat; 6). Kredit adalah jembatan untuk meningkatkan pendapatan nasional; 7). Kredit adalah juga sebagai alat hubungan ekonomi internasional.

Dari uraian tersebut menunjukan bahwa bank sebagai kreditur memiliki peranan yang sangat penting dalam fungsinya untuk pengembangan suatu usaha, karena bank adalah merupakan lembaga keuangan yang memiliki modal besar dan dapat memberikan fasilitas kredit yang memadai. Hal ini di sebabkan karena tugas utama bank adalah menghimpun dana dari masyarakat dan menyalurkannya dalam bentuk kredit, sehingga sebelum bank memberikan kredit kepada calon debitur (nasabah) haruslah memiliki keyakinan bahwa debitur ada kesanggupan untuk melunasi utang nya serta memegang prinsip kehati-hatian seperti yang di tegaskan dalam pasal 8 ayat (1) UndangUndang no 7 Tahun 1992 telah diubah oleh undang-undang no 8 Tahun 1998 yang di dalamnya menyatakan sebagai berikut:

Dalam memberikan kredit atau pembiayaan berdasarkan prinsif syariah, bank umum wajib mempunyai keyakinan berdasarkan analisis yang mendalam atas itikad dan kemampuan serta kesanggupan nasabah debetur untuk melunasi utang nya atau mengembalikan pembiayaan di maksud sesuai dengan yang di perajan jikan "

\section{B. METODE}

\section{Jenis Penelitian}

Penelitian merupakan salah satu cara yang tepat untuk memecahkan masalah. Selain itu penelitian juga dapat digunakan untuk menemukan, mengembangkan dan menguji kebenaran. Dilaksanakan untuk mengumpulkan data

1 Peter mahmud marzuki, Hukum jaminan Indonesia, Elips, jakarta, 1998, hal 59 guna memperoleh pemecahan masalah atau mendapatkan jawaban atas pokokpokok permasalahan yang dirumuskan dalam Bab I Pendahuluan, sehingga diperlukan rencana yang sistematis. Metodelogi merupakan suatu logika yang menjadi dasar suatu penelitian ilmiah. Oleh karenanya pada saat melakukan penelitian seseorang harus memperhatikan ilmu pengetahuan yang menjadi induknya. ${ }^{2}$

Hal tersebut menjadi sangat penting karena akan mempengaruhi hasil yang akan didapatkan. Seperti hasil penelitian dalam bidang ilmu teknik akan berbeda dengan penelitian dibidang ilmu hukum. Disamping itu untuk mendapatkan hasil yang memuaskan, seorang peneliti harus memperhatikan metode yang digunakan.

Pada penelitian hukum ini, peneliti menjadikan bidang ilmu hukum sebagai landasan ilmu pengetahuan induknya, oleh karena itu maka penelitian yang digunakan adalah penelitian hukum. Menurut Soerjono Soekanto yang dimaksud dengan penelitian hukum adalah kegiatan ilmiah yang didasarkan pada metode, sistematika, dan pemikiran tertentu yang bertujuan untuk mempelajari satu atau segala hukum tertentu dengan jalan menganalisanya. ${ }^{4}$ Dalam penelitian hukum juga dilakukan pemeriksaan yang mendalam terhadap fakta-fakta hukum untuk selanjutnya digunakan dalam menjawab permasalahan-permasalahan. Agar tidak terjebak pada kesalahan yang umumnya terjadi dalam sebuah penelitian hukum dengan memaksakan penggunaan formal penelitian empiris dalam ilmu sosial terhadap penelitian normatif (penelitian yuridis normatif), maka penting sekali mengetahui dan menentukan jenis penelitian sebagai salah satu komponen dalam metode penelitian. Sebab ketepatan

\footnotetext{
2 Ronny Hanintijo Soemitro, Metodologi Penelitian Hukum dan Jurumetri, Ghalia Indonesia ,Jakarta, , 1998, Hal. 9

4 Soerjono Soekanto, Pengantar Penelitian Hukum, UI, Jakarta, 1986, hal 43
} 
dalam metode penelitian akan sangat berpengaruh terhadap proses dan hasil penelitian hukum.

\section{Pendekatan Penelitian}

Pendekatan penelitian adalah metode atau cara mengadakan penelitian. Dari ungkapan konsep tersebut jelas bahwa yang dikehendaki adalah suatu informasi dalam bentuk deskripsi dan menghendaki makna yang berada di balik bahan hukum.

Sesuai dengan jenis penelitiannya yakni penelitian hukum normatif (yuridis normatif), maka dapat digunakan lebih dari satu pendekatan. Dalam penelitian ini digunakan pendekatan perundangundangan (Statute Approach) dan pendekatan konsep (conceptual approach).

Pendekatan perundang-undangan dilakukan untuk meneliti aturan perundang-undangan yang mengatur mengenai perbankan dan hak tanggungan yakni Undang-undang No. 10 Tahun 1998 Tentang Perbankan dan Undang-undang No. 4 Tahun 1996 Tentang Hak Tanggungan. Sedangkan pendekatan perbandingan dilakukan untuk melihat bagaimana antara satu hukum yang mengatur ketentuan yang serupa namun tidak searah dengan hukum lainnya, sehingga nantinya akan ditemukan sebuah titik temu baik kesamaan maupun perbedaan yang akan sangat membantu dalam proses analisis.

\section{Jenis Bahan Hukum}

Dalam penelitian hukum tidak dikenal adanya data, sebab dalam penelitian hukum khususnya yuridis normatif sumber penelitian hukum diperoleh dari kepustakaan bukan dari lapangan, untuk itu istilah yang dikenal adalah bahan hukum. Dalam penelitian hukum normatif bahan pustaka merupakan bahan dasar yang dalam ilmu penelitian umumnya disebut bahan hukum sekunder. Dalam bahan hukum sekunder terbagi bahan hukum primer dan sekunder.

a. Bahan Hukum Primer

Bahan hukum primer merupakan bahan hukum yang bersifat autoritatif artinya mempunyai otoritas. Adapun bahan huum primer terdiri dari :
1) Kitab Undang-Undang Hukum Perdata

2) Undang-undang No. 10 Tahun 1998 Tentang Perbankan

3) Undang-undang No. 4 Tahun 1996 Tentang Hak Tanggungan

b. Bahan Hukum Sekunder

Merupakan bahan hukum yang bersifat membantu atau menunjang bahan hukum primer dalam penelitian yang akan memperkuat penjelasan di dalamnya. Diantara bahan-bahan hukum sekunder dalam pnelitian ini adalah buku-buku, thesis, jurnal, dokumendokumen yang mengulas tentang perjanian, perbankan dan hak tanggungan yang nantinya akan dijadikan sebagai analisis dalam penelitian ini.

c. Bahan Hukum Tersier

Merupakan bahan hukum yang memberikan petunjuk atau penjelasan terhadap bahan hukum primer dan sekunder seperti kamus hukum, ensiklopedia, dan lain-lain.

\section{Metode Penulusuran Bahan Hukum}

Penulusuran bahan hukum dalam penelitian normatif ini diperoleh dari bahan-bahan berupa literatur, dan stelah bahan-bahan hukum tersebut terkumpul kemudian diinventarisir serta dialakukan pengelompokan sesuai dengan bahan yang akan diteliti yaitu masalah-masalah yang berkaitan dengan pelaksanaan eksekusi hak tanggungan dalam rangka penyelesaian kredit macet di pengadilan.

\section{Tehnik Analisis Bahan Hukum}

Bahan hukum yang sudah terkumpul dan disusun secara teratur, kemudian dianalisis secara deduktif yaitu menarik kesimpulan dari suatu permasalahan yang bersifat umum terhadap permasalahan konkret yang dihadapi. Analisis yang dilakukan dengan data kualitatif, ini akan mendekripsikan proses eksekusi Hak Tanggungan dalam upaya menyelesaikan kredit macet di Pengadilan Negeri.

\section{PEMBAHASAN}

Dengan adanya lembaga perbankan tersebut tentunya akan dapat mendorong peningkatan partisipasi masyarakat dalam 
pembangunan yang bertujuan untuk mewujudkan masyarakat yang sejahtera, adil dan makmur dalam kehidupan sehariharinya. Sehubungan dengan pentingnya peranan bank terebut oleh Mariam Darus Badrul Zaman dikatakan sebagai berikut:

Perbankkan memiliki peranan yang strategis dalam trilogi pembangunan, karena perbankan adalah suatu wahana yang dapat menghimpun dan menyalurkan dana masyarakt secara efektif, dan efisien, yang dengan berasaskan demokrasi ekonomi mendukung pelaksanaan pembangunan nasional dalam rangka meningkatkan pemerataan pembangunan dan hasil-hasilnya, pertumbuhan ekonomi dan stabilitas nasional kearah peningkatan taraf hidup rakyat banyak"

Hubungan hukum yang mewujudkan adanya suatu perjanjian kredit tersebut mengharuskan pihak bank untuk memperhatikan adanya colateral (anggunan) yang diberikan oleh debitur, karena anggunan adalah merupakan lembaga jaminan yang bersifat kebendaan yang memiliki ciri-ciri yaitu mempunyai hubugan langsung dengan benda tertentu milik debitur dan dapat dipertahankan maupun ditujukan kepada siapa saja serta dapat mengikuti bendanya ditangan siapapun berada (Desuite). Lembaga jaminan yang bersifat kebendaan ini meliputi Gadai, Hipotik, Fiducia dan hak tanggungan.

Pada umumnya jaminan yang paling di ingini oleh bank selaku pemberi kredit adalah berupa tanah, dan hal ini di katakan oleh Bachtiar Effendi yang bahwasannya mengatakan "bahwa dewasa ini barang jaminan yang dirasa cukup aman sebagai jaminan dalam pinjam meminjam uang adalah tanah, karena tanah tidak mudah musnah atau hilang dll ". Senada dengan apa yang katakan oleh Bachtiae Effendi tersebut didukung oleh pendapat dari Effendi Perangin yang mengatakan sebagai berikut :

"tanah merupkan barang
jaminan untuk pembayaran
utang yang paling disukai oleh
lembaga ke uangan yang
memberikan pasilitas kredit.

sebab tanah pada umumnya mudah dijual, harganya terus meningkat, mempunyai bukti hak, sulit digelapkan dan dapat dibebani hak tanggungan yang memberikan hak istimewa kepada kreditur" 7

Agar tanah sebagai jaminan kredit dapat memenuhi kehendak kreditur maka tanah tersebut haruslah dibebani sebagai hak tanggungan sebagai jaminannya. Tanah yang di bebani dengan hak tanggungan sebagai sarana untuk pembayaran utang tersebut mengandung pengertian bahwa tanah tertentu oleh orang yang berhak memberikan jaminan disediakan secara khusus kepada kreditur untuk lebih meyakinkan bahwa utang debitur akan dilunasi pada saat yang diperjanjikan. Jika debitur mengingkari janjinya, maka kreditur berhak menjual tanah yang dibebani hak tanggungan tersebut dan mengambil uang hasil penjualannya untuk di perhitungkan sebagi pembayaran utang debitur. Jaminan yang dikehendaki oleh kreditur sedemikian rupa itu akan menimbulkan konsekwensi bahwa kreditur mempunnyai hak istimewa yaitu piutangnya dilunasi terlebih dahulu dari hasil penjualan barang yang di jaminkan dengan mengesampingkan kreditur lain. Disamping itu benda yang dijaminkan itu sudah dijual, di hibahkan atau dengan cara lain dan bukan lagi menjadi milik yang menjaminkan, kreditur tetap berhak menjual barang jaminan itu dan mengambil hasil penjualannya untuk pelunasan piutangnya (Droit desuit). Dari hal tersebut telah menunjukan bahwa kreditur memiliki kedudukan yang kuat untuk mendapatkan tagihan yang didahulukan dari kreditur lainnya.

Berkaitan dengan hal tersebut J. Satrio mengatakan bahwa tagihan yang dimiliki oleh kreditur tersebut disebut sebagai tagihan Preferen, sedangkan krediturnya disebut sebagai kreditur Preferen "8.

\footnotetext{
7 Mariam Darus Badrul Zaman, Aneka Hukum Bisnis, alumni, Bandung, 1994, hal 106.

8 J. Satrio, Hukum jaminan, Hak-hak kebendaan, Citra Aditya Bhakti, Bandung, 1994, hal 28.

8 Muhammad Djumhana Rabasia bank, ketentuan dan penerapannya di Indonesia, Citra Aditya Bhakti, Bandung, 1996, hal 159.
} 
Hak tanggungan sebagai lembaga jaminan khusus lahir karena adanya perjanjian antara bank dan nasabah (Debitur) yang bertujuan untuk melindungi kreditur apabila terjadi kredit macet, karena setiap bank pasti akan menghadapi kredit bermasalah, bahkan dikatkan oleh Muhamad Jumhana Bahwa setiap bank pasti menghadapi kredit yang bermasalah bank tanpa kredit yang bermasalah merupakan hal yang aneh "9. Dalam hubungan antara bank dengan debitur tersebut terdapat adanya dua perjanjian yaitu: Perjanjian kredit sebagai perjanjian pokok dan perjanjian pembebanan hak tanggungan sebagai perjanjian tambahan. Pembebanan jaminan yang dilakukan oleh pemberi jaminan tersebut bertujuan untuk mendapatkan fasilitas kredit baik dari bank maupun lembaga keuangan non bank. Pada umumnya jaminan yang diserahkan kepada kreditur (Bank) adalah jaminan materil yaitu jaminan yang berupa hak-hak kebendaan, sepeti jaminan atas benda tidak bergerak berupa tanah. Agar pembebanan jaminan tersebut sesuai dengan aturan Hukum, maka akta pembebanannya haruslah dilakukan oleh PPAT serta harus didaftarkan di kantor pertanahan. Pendaftaran hak tanggungan ini adalah merupakan perwujudan asas publisitas yang merupakan salah satu pilar didalam sistem pendaftaran hak atas tanah menurut PP no 10 Tahun 1961 yang telah diperbaharui oleh PP no 24 Tahun 1997. Adapun tujuan dari adanya pendaftaran tersebut disamping memenuhi asas publisitas juga bertujuan untuk mendapatkan apa yang disebut dengan sertipikat hak tanggungan yang merupakan sarana untuk menyelesaian kredit macet, yaitu dengan cara melakukan eksekusi secara lagsung terhadap benda jaminan milik debitur cedera janji tanpa harus melalui proses gugatan di pengadilan negeri. Sertipikat hak tanggungan yang dapat dilakukan eksekusi secara langsung tanpa adanya proses gugatan dipengadilan tesebut.

\section{KESIMPULAN}

1. Pengadilan Negeri dalam menjalankan eksekusi sertifikat hak tanggungan tidak saja meliputi sebagaimana ketentuan yang diamanatkan dalam Pasal 6 UndangUndang Hak Tanggungan, Pasal 224 $\mathrm{HIR} / 258 \mathrm{RBg}$, juga mamberikan pertimbangan hukum terhadap kreditor dan debitor. Kemudian dalam menyikapi permasalahan mengenai eksekusi Hak Tanggungan tersebut dengan berlandaskan pada ketentuan Pasal 218 (2) RBg maka dalam hal debitor/ termohon lelang tidak bersedia keluar dari obyek Hak Tanggungan atau jaminan atau barang yang dilelang maka cukup mengajukan permohonan kepada Ketua Pengadilan Negeri untuk dilakukan eksekusi pengosongan dan hal ini dalam beberapa kesempatan telah dilaksanakan dan berjalan dengan baik, sekalipun dalam proses atau pelaksanaan eksekusi Hak Tanggungan tersebut salah satunya dilakukan dengan bantuan kekuatan hukum.

2. Akibat hukum yang timbul sebagai konsekuensi dari tugas Pengadilan Negeri dalam menjalankan eksekusi jaminan Hak Tanggungan untuk menyelesaikan kredit macet adalah debitor harus patuh untuk melunasi hutangnya, bila tidak patuh maka dipaksa melalui lelang, cekal dan atau paksa badan dan kalau keberatan terhadap eksekusi dapat mengajukan gugatan, sedangkan terhadap kreditor/bank yang tidak puas atas pengurusan hak tanggungan dapat mengurus sendiri piutangnya, serta terhadap Pihak Ketiga yang keberatan dapat mengajukan perlawanan (derdenverzet).

\section{E. DAFTAR PUSTAKA}

Peter mahmud marzuki, Hukum jaminan Indonesia, Elips, jakarta, 1998

Direktorat Hukum Bank Indonesia, UndangUndang Perbankan, Jakarta, 1998

Mariam Darus Badrul Zaman, Aneka Hukum Bisnis, alumni, Bandung, 1994

Setiawan, Aneka Masalah Hukum, Dan Hukum Acara Perdata, Alumni, Bandung, 1992

Bachtiar Effendi, Kumpulan Tulisan Tentang Hukum Tanah, Alumni Bandung, 2004 
Effendi Perangin, Praktek Penggunaan Tanah Sebagai Jaminan Kredit, Rajawali, Jakarta, 1987

Direktorat Hukum Bank Indonesia, UndangUndang Perbankan, Jakarta, 1998

Mariam Darus Badrul Zaman, Aneka Hukum Bisnis, alumni, Bandung, 1994

Bachtiar Effendi, Kumpulan Tulisan Tentang Hukum Tanah, Alumni Bandung, 2004

Effendi Perangin, Praktek Penggunaan Tanah Sebagai Jaminan Kredit, Rajawali, Jakarta, 1987

J. Satrio, Hukum jaminan, Hak-hak kebendaan, Citra Aditya Bhakti, Bandung, 1994

Muhammad Djumhana Rabasia bank, ketentuan dan penerapannya di Indonesia, Citra Aditya Bhakti, Bandung, 1996

Ronny Hanintijo Soemitro, Metodologi Penelitian Hukum dan Jurumetri, Ghalia Indonesia ,Jakarta, , 1998.

Soerjono Soekanto, Pengantar Penelitian Hukum, UI, Jakarta. 